\title{
The Chiropractic Care of Children
}

\author{
Joel Alcantara, D.C., Jeanne Ohm, D.C., and Derek Kunz, B.S.
}

\begin{abstract}
Objective: The objective of this study was to characterize the practice of pediatric chiropractic.

Design: The study design was a cross-sectional descriptive survey.

Settings/location: The settings were private practices throughout the United States, Canada, and Europe.

Participants: The participants were 548 chiropractors, the majority of whom are practicing in the United States, Canada, and Europe.

Main outcome measures: Practitioner demographics (i.e., gender, years in practice, and chiropractic alma mater), practice characteristics (i.e., patient visits per week, practice income reimbursement), and chiropractic technique were surveyed. The practitioners were also asked to indicate common indicators for pediatric presentation, their practice activities (i.e., use of herbal remedies, exercise and rehabilitation, prayer healing, etc.), and referral patterns.

Results: A majority of the responders were female with an average practice experience of 8 years. They attended an average of 133 patient visits per week, with $21 \%$ devoted to the care of children ( $<18$ years of age). Practice income was derived primarily from out-of-pocket reimbursement with charges of an average of $\$ 127$ and $\$ 42$ for the first and subsequent visits, respectively. These visits were reimbursed to address common conditions of childhood (i.e., asthma, ear infections, etc.). Approach to patient care was spinal manipulative therapy (SMT) augmented with herbal remedies, exercises, rehabilitation, and so on. Wellness care also figured prominently as a motivator for chiropractic care. Fifty-eight percent (58\%) indicated an established relationship with an osteopathic or medical physician. Eighty percent $(80 \%)$ of the responders indicated referring patients to medical practitioners while only $29 \%$ indicated receiving a referral from a medical/osteopathic physician.

Conclusions: The chiropractic care of children is a significant aspect of the practice of chiropractic. Further research is warranted to examine the safety and effectiveness of this popular nonallopathic approach to children's health.
\end{abstract}

\section{Introduction}

C ONTEMPORANEOUS WITH THE ADUlt USE of complementary and alternative medicine (CAM) is the burgeoning interest in CAM therapies for children. In a follow-up study on the use of CAM by adults, Eisenberg et al. ${ }^{1}$ determined that CAM utilization increased from $34 \%$ in the early 1990 s to $42 \%$ in the late 1990s. During this same time period, CAM pediatric utilization increased from $11 \%$ to $20 \%{ }^{2}$ Reports indicate that children comprise approximately $8 \%-11 \%$ of all chiropractic visits. These visits are to address a myriad of diagnoses such as pain, respiratory and gastrointestinal tract problems, ear infections, enuresis, and hyperactivity. ${ }^{3-5}$ In a study characterizing the chiropractic care of children, Lee and colleagues ${ }^{3}$ extrapolated that pediatric patients made some 30 million visits to chiropractors in 1997 . This was a 50\% increase during a 4-year period from a previous estimate of 20 million visits. ${ }^{6}$
In an analysis of CAM use by adults and children in 2007, Barnes and colleagues ${ }^{7}$ found that of the practitioner-based CAM therapies, chiropractic was widely utilized. Given the eclectic practice of chiropractors that incorporate a number of CAM therapies beyond spinal manipulative therapy (SMT) (i.e., nutritional supplements, massage, diet and exercise, etc.), the chiropractic care of children represents a significant aspect of children's health.

To further characterize the chiropractic care of children, commonly referred to as pediatric chiropractic, we surveyed chiropractors from the membership of the International Chiropractic Association (Media, PA).

\section{Materials and Methods}

A cross-sectional descriptive survey of chiropractors from the membership of the International Chiropractic Pediatric 
Association (ICPA) (Media, PA) ${ }^{8}$ was implemented to characterize the care of children. The survey instrument was pilot tested with 15 chiropractors and revisions were made as appropriate for implementation. A letter of invitation was sent out by e-mail to 1550 ICPA members to participate in a survey study. Potential responders were assured that the survey was voluntary and anonymous and would not violate patient confidentiality. Of the invited 1550 chiropractors, 47 invitations were returned as "undeliverable," providing a total of 1503 potential responders. A response rate of 37\% was calculated based on 548 completed responses. Despite the low response rate, the sample size was relatively large. We did not follow up with nonresponders to increase the response rate or find out the reasons for a nonresponse.

\section{Survey Content}

The survey was motivated, in part, by the publication of Lee and colleagues. ${ }^{3}$ The Lee and colleagues ${ }^{3}$ study was based on questions from the National Ambulatory Medical Care Survey from the National Center for Health Statistics (Hyattsville, MD) and developed in conjunction with a licensed chiropractor to characterize the chiropractic care of children in the Boston Metropolitan area. The survey for this study was 2 pages long and required approximately 10 minutes to complete. The survey content included practitioner sociodemographics (i.e., gender, years in practice, and chiropractic alma mater), practice characteristics (i.e., number of patient visits per week, the number of pediatric patient visits per week), the proportion of practice income reimbursed by insurance or paid out-of-pocket, and the chiropractic technique utilized. The responders were also queried on the five most common indicators (i.e., presenting complaints, motivation for care) for pediatric presentation and the type of care rendered (i.e., SMT, herbs and dietary supplements, wellness care, exercise and rehabilitation, prayer healing, and others). Finally, the responders were asked their referral patterns with respect to medical providers.

\section{Statistical Analysis}

Data were entered in a Portable Document Format (.pdf) through Adobe Reader (Adobe Systems). From this PDF, an Extensible Markup Language (XML) file was created containing the data entered in the original form. Using Adobe Acrobat (Adobe Systems), the XML files were converted to a single Comma Separated Value (.csv) file, which was exported to a spreadsheet (Excel, Microsoft Corp.) and analyzed using descriptive statistics.

\section{Results}

\section{Demographics and training}

A total of 548 licensed chiropractors (332 females: 216 males) completed the survey. Approximately $86 \%$ of the responders practiced in the United States with the remaining from Canada $(13 \%)$ and elsewhere $(1.0 \%)$. The responders have been in practice an average of 8.02 years (median $=6$ years; mode $=6$ years) with alma maters from Life University $(17 \%)$, the Palmer University System (16\%), Parker College of Chiropractic (7\%), and Cleveland (Kansas City) College of Chiropractic (4\%). A majority of the responders $(N=340 ; 62 \%)$ were trained in the ICPA Pediatric Certifica- tion program, a 180-hour postgraduate program on pediatric chiropractic. Approximately $14 \%(N=79)$ completed or were currently enrolled in the ICPA Pediatric Diplomate program, a 360-hour postgraduate course with an emphasis on specialty care for children.

\section{Practice characteristics and fee structure}

The responders attended to an average of 133 patient visits per week (median $=100$ visits; mode 100 visits). Patient visits for those less than 18 years of age averaged 28 visits per week (median $=20$ visits; mode $=10$ visits) or $21 \%$ of the average weekly patient visits. The average cost of an initial visit (i.e., initial consultation/examination and care) was $\$ 127$, with a follow-up visit averaging $\$ 42$. The responders were asked to provide the proportion of their practice income derived from "insurance" (i.e., third-party payor) or "cash" (i.e., out-of-pocket); insurance reimbursement averaged $53 \%$ while an average of $44 \%$ was derived from cash. Specific to the care of children, the proportion of income derived from insurance reimbursement averaged 36\% while out-of-pocket reimbursement averaged $60 \%$. Twenty-eight percent $(28 \%)$ of the responders indicated having been denied reimbursement from "insurance" for pediatric patient visits. With respect to referral patterns on the chiropractic care of children, $58 \%(N=320)$ of the respondents indicated as having a specific medical or osteopathic physician to refer patients. Eighty percent $(N=440)$ of the responders indicated having advised parents to seek medical care for their child when appropriate. This is in contrast to only $29 \%$ $(N=161)$ of the responders indicating ever receiving a referral from such practitioners.

\section{Practice activities}

When asked to characterize the care rendered to children, the responders indicated performing "chiropractic adjustments" (100\%; $N=548)$ followed by "wellness care" $(90 \%$; $N=494)$, the use of herbal remedies $(44 \% ; N=244)$, exercise and rehabilitation $(42 \% ; N=235)$ and prayer healing $(6 \%$; $N=36$ ). The chiropractic techniques commonly utilized to perform the chiropractic SMT were: Diversified Technique ${ }^{9}$ $(87.02 \% ; N=503)$, Activator Methods ${ }^{10}$ (69\%; $\left.N=382\right)$, Thompson Technique ${ }^{11}(60 \% ; N=331)$, Cranial-Sacral Technique $^{12}(40 \% ; N=220)$, the Gonstead Technique ${ }^{13}(32 \%$; $N=180)$, Sacro-Occipital Technique ${ }^{14}(29 \% ; N=159)$ and Chiropractic Biophysics Technique ${ }^{15}(13 \% ; N=73)$ (see Table 1 for brief descriptions of these techniques). The pediatric conditions motivating a child's presentation for chiropractic care are presented in Table 2. Specific conditions indicated were problems with the ear, nose, and throat (i.e., otitis media), digestive disorders, musculoskeletal problems, and so on.

\section{Discussion}

In one of the early studies examining the use of unconventional medicine, Thomas et al. ${ }^{16}$ determined that of 2152 "non-physician British practitioners surveyed, only $2 \%$ of their patient population were those under 16 years of age." Contrasted to recent studies, the use of CAM by children has grown substantially. Epidemiological studies indicate that in children suffering from chronic diseases such as asthma, ${ }^{17}$ 
Table 1. Chiropractic Techniques Commonly Utilized in the Chiropractic Care of Children

\begin{tabular}{|c|c|}
\hline Technique & Description \\
\hline Diversified technique & $\begin{array}{l}\text { SMT characterized as high-velocity, low-amplitude (HVLA) thrusts to sites of spinal } \\
\text { and extraspinal dysfunctional articulations. }\end{array}$ \\
\hline Activator methods & $\begin{array}{l}\text { A handheld, spring-loaded instrument that delivers a site-specific low-force-type thrust } \\
\text { to spinal and extraspinal dysfunctional articulations. }\end{array}$ \\
\hline Thompson technique & $\begin{array}{l}\text { A variation of the Diversified technique that utilizes a special table with several } \\
\text { "drop-piece" segments. When the thrust is delivered, the table "drops" a small distance. } \\
\text { The drop pieces assist the thrust while minimizing the force used for the delivery of SMT. }\end{array}$ \\
\hline Craniosacral technique & $\begin{array}{l}\text { Not a chiropractic technique per se but a manual therapy that applies a sustained } \\
\text { and prolonged force (non-HVLA) to correct cranial segmental dysfunction. }\end{array}$ \\
\hline Gonstead technique & $\begin{array}{l}\text { Developed by Clarence Gonstead, D.C., this is a segment-specific HVLA-type thrust } \\
\text { technique that incorporates the use of X-ray analysis (spinography), and temperature } \\
\text { gradient instrumentation (i.e., nervoscope) to assist in the clinical decision-making } \\
\text { (i.e., what spinal segment(s) in location sites of spinal segmental dysfunction). }\end{array}$ \\
\hline Sacro-occipital technique & $\begin{array}{l}\text { Developed by Major Bertrand DeJarnette, D.C., this is a category system of analysis } \\
\text { and treatment to remove body distortions. }\end{array}$ \\
\hline Chiropractic biophysics & $\begin{array}{l}\text { Developed by Don Harrison, D.C., this utilizes manual techniques in addition to drop table, } \\
\text { hand-held instruments, exercises, and traction to correct segmental as well as global } \\
\text { postural distortions. }\end{array}$ \\
\hline
\end{tabular}

SMT, spinal manipulative therapy.

attention deficit hyperactivity disorder, ${ }^{18}$ and cancer, ${ }^{19} \mathrm{CAM}$ use may range from $11 \%$ to $80 \%$. Weighted estimates of the amount paid for pediatric expenditures on CAM visits and remedies were $\$ 127$ million and $\$ 22$ million, respectively. ${ }^{20}$ According to Kemper and colleagues, ${ }^{21}$ faced with the continuing popularity and use of CAM therapies by children, the American Academy of Pediatrics convened and charged the Task Force on Complementary and Alternative Medicine to address issues related to the use of CAM therapies in children and to develop resources to educate physicians and their patients/guardians. As indicated earlier, chiropractic care represents the most common type of CAM therapy for children, particularly when one considers the eclectic practice of chiropractic utilizing herbs, nutritional supplement, massage, and so on in addition to SMT. ${ }^{7}$ This is also reflected in the finding that the proportion of chiropractic patients under 17 years of age has increased substantially by $8.5 \%$ from $9.7 \%$ in 1991 to $18.2 \%$ in $2003 .^{22}$

The 1997 survey study by Lee and colleagues ${ }^{3}$ characterized the chiropractic care of children in the Boston metropolitan area. The authors extrapolated that approximately 30 million pediatric visits were made to chiropractors during the year of their study. This represented approximately $\$ 1$ billion in health care cost with $\$ 510$ million being paid outof-pocket by families. Based on similar calculations with data (i.e., patient visits) obtained in our study, we estimated some 86 million visits per year were made to chiropractors in 2007. Certainly this may be an overestimate given the bias of our responders toward a practice specializing in pediatric chiropractic. Lee and colleagues ${ }^{3}$ characterized the chiropractic care of children based on a $60 \%$ response rate $(N=90)$ from a pool of 150 chiropractors practicing within the Boston metropolitan area. Although our survey study reported a much lower response rate (i.e., 37\%), our data were derived from a larger sample $(N=548$ versus $N=90)$ of chiropractors, with the majority of responders practicing throughout the United States. The study by Lee and colleagues ${ }^{3}$ provided the foundation and impetus to continue the work on this subject. To the extent that one can make a comparison-ceteris paribus_-"all other things being equal" —an analysis of the results from this study is made in the context of the results obtained by Lee and colleagues ${ }^{3}$ and the relevant literature. With respect to practitioner demographics and training, our responders were predominantly female, unlike those of the Lee and colleagues ${ }^{3}$ study. Furthermore, a greater proportion of our responders had postgraduate training in pediatric chiropractic (Table 3). This may reflect a gender bias toward specialty practices such as pediatric chiropractic. In terms of practice characteristics (Table 4), our responders, on average, attended to a greater number of patient visits weekly, both in general terms and with respect to pediatric

Table 2. Common Pediatric Conditions Addressed by Chiropractors in Practice

\begin{tabular}{lcc}
\hline Condition & $\mathrm{N}$ & \% Response \\
\hline Wellness care & 378 & 16.67 \\
Ear, nose, and throat & 354 & 15.61 \\
Digestive & 295 & 13.00 \\
Musculoskeletal problems & 214 & 9.44 \\
ADD/ADHD & 112 & 4.94 \\
Headaches & 111 & 4.89 \\
Immune enhancement & 105 & 4.63 \\
Asthma & 83 & 3.66 \\
Scoliosis & 81 & 3.57 \\
Injury: sports & 78 & 3.44 \\
Injury: other & 77 & 3.39 \\
Allergies & 55 & 2.43 \\
Postural improvement & 53 & 2.34 \\
Postbirth checkup & 52 & 2.29 \\
Behavioral infants & 49 & 2.16 \\
Neurosensory disorders & 46 & 2.03 \\
Torticollis & 42 & 1.85 \\
Injury: birth & 37 & 1.63 \\
Asthma/allergies & 35 & 1.54 \\
Injury: motor vehicle collision & 11 & 0.49 \\
\hline
\end{tabular}

ADD/ADHD, attention deficit disorder/attention deficit hyperactivity disorder. 
Table 3. Practitioner Demographics and Training

\begin{tabular}{lcc}
\hline & Alcantara et al. 2009 survey & Lee et al. ${ }^{3}$ 2000 survey \\
\hline $\begin{array}{l}\text { Practitioner gender } \\
\text { Average years in practice } \\
\text { Postgraduate training in pediatric chiropractic }\end{array}$ & $60 \%$ Female $(N=328)$ & $65 \%$ Male $(N=59)$ \\
& $\begin{array}{c}14 \% \text { Diplomate }(N=79), 62 \% \\
\text { Certification }(N=358)\end{array}$ & $2 \%(N=18)$ \\
\hline
\end{tabular}

visits. Interestingly, the peer recommended pediatric chiropractors in the Lee and colleagues ${ }^{3}$ study attended to a similar number of pediatric patient visits per week as in our study. In terms of fee structure, our responders indicated a higher fee for the initial visit as well as subsequent visits. A 10 -year time-span between our study and that of Lee and colleagues $^{3}$ may account for the differences due to inflation, higher cost of living, and so on. Our study documents a slightly higher proportion of practice income derived from a "cash" practice. This may reflect the trend toward a "cash practice" by pediatric chiropractic practioners. ${ }^{23}$ Both the Lee et al. $^{3}$ responders and the responders of this study report a larger proportion of their practice income from out-of-pocket reimbursement, unlike the findings from the Job Analysis of Chiropractic $2005^{22}$ that found only $21.2 \%$ of its responders deriving income from "cash" with a larger percentage of income derived from insurance reimbursement (i.e., Medicaid, Private Insurance, Managed Care, etc.). With respect to patient referrals, the findings of our study indicate that our responders are willing participants in this new era of integrative medicine. ${ }^{24}$ With respect to the chiropractic techniques utilized, our study finding provides a more comprehensive listing of techniques. As for the specific types of care rendered, our practitioners confirm an eclectic practice with chiropractic SMT as the primary approach to patient care augmented by adjunctive therapies such as herbal remedies, rehabilitation and exercise, and so on. With respect to the types of pediatric conditions motivating chiropractic care, the vast majority of our respondents indicated conditions of the nonmusculoskeletal type (Table 2). Not surprisingly, this is quite different from the chiropractic care of adults, which involves mainly musculoskeletal problems, particularly neck pain and low back pain. ${ }^{25}$ The study findings by Hawk and colleagues ${ }^{26}$ found that one of the variables for likely presenting with nonmusculoskeletal complaints was age less than 14 years. Our study findings on the clinical presentation of children are consistent with the findings of previous studies. In a study to determine CAM use by children, Spigelblatt et al. ${ }^{4}$ found that, in addition to chiropractic therapy being the most widely utilized form of alternative medicine, nonmusculoskeletal complaints such as ear, nose, and throat, respiratory problems, and so on were more common than musculoskeletal complaints. This is similar to studies examining CAM utilization (in general) by pediatric patients. ${ }^{27}$ However, our findings are not consistent with previous chiropractic studies characterizing the chiropractic care of children. Nyiendo and Olsen, ${ }^{5}$ in characterizing the visits of 217 children at a chiropractic teaching clinic, found that $42 \%$ suffered from musculoskeletal complaints and only $20 \%$ from nonmusculoskeletal complaints. Verhoef and Papadopoulos, ${ }^{28}$ in a cross-sectional survey of 1200 Canadian chiropractors (response rate of 59\%), found that musculoskeletal complaints, headaches, and muscular sprain/strain dominated the types of indicated pediatric clinical presentations. A significant proportion of our responders indicated "wellness care" as a motivation for the chiropractic care of children. This is not unexpected given the following. Astin ${ }^{29}$ found that adults utilize CAM therapy not so much because of their dissatisfaction with medicine but rather because their world view and health beliefs are congruent with those of the CAM practitioners. As pointed out by Barnes and colleagues, ${ }^{7}$ children of CAM users are five times more likely to use CAM compared to children of nonCAM users. Chiropractic was founded on the theoretical and clinical framework of holism and vitalism with an emphasis on prevention and health promotion-all within the purview of wellness care. By describing the clinical presentations of 320 Australian adolescents, Ebrall ${ }^{30}$ was the first to describe wellness care as a motivation for parents to present their children for chiropractic care. Rubin, ${ }^{31}$ in triaging the clinical presentations of both children and pregnant women, found "wellness care" as a motivation for children to present for chiropractic care. Based on a convenience sample of international Sacro-Occipital Technique practitioners, Blum and colleagues $^{32}$ found that $40 \%$ of chiropractic patient visits were initiated for the purposes of health enhancement and/ or disease prevention. Alcantara and colleagues, ${ }^{33}$ in addressing the safety and effectiveness of the chiropractic care

Table 4. Practice Characteristics and Fee Structures

\begin{tabular}{lrr}
\hline & Alcantara et al. 2009 survey & Lee et al. ${ }^{3}$ 2000 survey \\
\hline Average weekly visits & 133 & 122 \\
Average weekly pediatric visits & 28 & $1126^{\mathrm{a}}$ \\
Average cost of initial visit & $\$ 127$ & $\$ 82$ \\
Average cost of subsequent visits & $\$ 42$ & $\$ 38$ \\
Average percent of practice income from cash practice & $53 \%$ & $\mathrm{~N} / \mathrm{A}$ \\
Average percent of practice income from insurance practice & $44 \%$ & $49 \%$ \\
\hline
\end{tabular}

\footnotetext{
${ }^{\text {a}}$ Peer-recommended pediatric practitioner.
}

N/A, not applicable. 
of children in a practice-based research setting, found that "wellness care" was also a significant motivator for clinical presentation. Wellness care may be a reflection of the paradigm shift in health and health care from a purely biomedical approach to a more holistic and vitalistic approach incorporating a biopsychosocial model. ${ }^{34}$

By the very nature of their research design, survey studies have inherent limitations and certainly must be accounted for in this study. First, the survey was confined to members of the ICPA. As such, selection bias is a concern and the results of this study may not be reflective of the views of the general chiropractic profession but rather those of the ICPA membership. Alternatively, membership with the ICPA is indicative of support of the mission and goals of this organization as it pertains to promoting the chiropractic care of children. In addition to the ICPA, the International Chiropractic Association (ICA) Pediatric Council and the American Chiropractic Association (ACA) Pediatric Council also promote the chiropractic care of children. Based on their membership referral list, the ICA Pediatric Council has 381 members while the ACA Pediatric Council has 54 members. This is a sharp contrast to the ICPA membership of over 2500 members. With respect to pediatric postgraduate seminars, the ICPA offered 134 seminars worldwide while the ICA had 6. In the realm of public education, the ICPA has an informative consumer Web site highlighting pediatric chiropractic and publishes Pathways to Family Wellness with distribution to holistic providers and parents internationally. Its 5th-year anniversary issue hit major U.S. bookstores in the spring of 2009. Given the dominance of the ICPA in pediatric chiropractic research, teaching, and public service, the results of our survey may more likely reflect the chiropractic care of children. Another limitation is recall bias where the data were self-reports of chiropractors rather than collection of data through independent means such as direct observation.

\section{Conclusions}

To the best of our knowledge, this study provides the largest database to characterize the practice of pediatric chiropractic in North America. With continuing popularity and utilization of chiropractic for adults and their children, we support further studies to examine the safety and effectiveness of pediatric chiropractic.

\section{Disclosure Statement}

This study was funded by the ICPA. Its mission is to promote the chiropractic care of children. The authors are affiliated with the organization and received funding in the preparation of this article.

\section{References}

1. Eisenberg DM, Davis RB, Ettner SL, et al. Trends in alternative medicine use in the United States, 1990-1997. JAMA 1998;280:1569-1575.

2. Ottolini MC, Hamburger EK, Loprieato JO, et al. Complementary and alternative medicine use among children in the Washington, DC area. Ambul Pediatr 2001; $1: 122-125$.

3. Lee AC, Li DH, Kemper KJ. Chiropractic care for children. Arch Pediatr Adolesc Med 2000;154:401-407.
4. Spigelblatt L, Laine-Ammara G, Pless IB, Guyver A. The use of alternative medicine by children. Pediatrics 1994;94 (6 pt 1):811-814.

5. Nyiendo J, Olsen E. Visit characteristics of 217 children attending a chiropractic college teaching clinic. J Manip Physiol Ther 1988;11:78-84.

6. Kassberg M. How chiropractors are manipulating your patients. Pediatric Manage 1993;November:22-23.

7. Barnes PM, Bloom B, Nahin RL. Complementary and alternative medicine use among adults and children: United States, 2007. Natl Health Stat Report 2009;12:1-23.

8. The International Chiropractic Pediatric Association. Online document at: www.icpa4kids.com Accessed June 22, 2009.

9. Bergmann TF, Peterson DH, Lawrence DJ. Chiropractic Technique: Principles and Procedures. New York: Churchill Livingstone, 1993.

10. Fuhr AW, Green JR, Colloca CJ, Keller TS. Activator Methods Chiropractic Technique. St. Louis: Mosby-Year Book, 1997.

11. Minardi J. The Complete Thompson Textbook-Minardi Integrated Systems. Oakville, ON, Canada: Minardi Publications, 2006.

12. Upledger JE. Craniosacral therapy. Phys Ther 1994;74:908-916.

13. Plaugher G. Textbook of Clinical Chiropractic: A Specific Biomechanical Approach. Baltimore: Williams \& Wilkins, 1992.

14. Rosen MG, Blum CL. Sacro occipital technique: Technique and analysis. Today's Chiropract 2003;32:22,24-26.

15. Harrison DE, Harrison DD, Haas JW, Oakley PA. Spinal Biomechanics for Clinicians, Volume I. Evanston, WY: Harrison CBP ${ }^{\circledR}$ Seminars, 2003.

16. Thomas KJ, Carr J, Westlake L, Williams BT. Use of nonorthodox and unconventional health care in Great Britain. BMJ 1991;302:207-210.

17. Reznik M, Ozuah PO, Franco K, et al. Use of complementary therapy by adolescents with asthma. Arch Pediatr Adolesc Med 2002;156:1042-1044.

18. Chan E, Rappaport LA, Kemper KJ. Complementary and alternative therapies in childhood attention and hyperactivity problems. J Dev Behav Pediatr 2003;24:4-8.

19. Sawyer MG, Gannoni AF, Toogood IR, et al. The use of alternative therapies by children with cancer. Med J Aust 1994;160:320-322.

20. Yussman SM, Ryan SA, Auinger P, Weitzman M. Visits to complementary and alternative medicine providers by children and adolescents in the United States. Ambul Pediatr 2004;4:429-435.

21. Kemper KJ, Vohra S, Walls R, Task Force on Complementary and Alternative Medicine, Provisional Section on Complementary, Holistic and Integrative Medicine. American Academy of Pediatrics. The use of complementary and alternative medicine in pediatrics. Pediatrics 2008;122: 1374-1386.

22. National Board of Chiropractic Examiners. Job Analysis of Chiropractic. Greeley, CO: National Board of Chiropractic Examiners, 2005.

23. National Center for Complementary and Alternative Medicine. National Institutes of Health. Paying for complementary and alternative medicine treatment: Information for patients. National Center for Complementary and Alternative Medicine National Institutes of Health. J Pain Palliat Care Pharmacother 2008;22:153-157.

24. Greeson JM, Rosenzweig S, Halbert SC, et al. Integrative medicine research at an academic medical center: Patient characteristics and health-related quality-of-life outcomes. J Altern Complement Med 2008;14:763-767. 
25. Hurwitz EL, Coulter ID, Adams AH, et al. Use of chiropractic services from 1985 through 1991 in the United States and Canada. Am J Public Health 1998;88:771-776.

26. Hawk C, Long CR, Boulanger KT. Prevalence of nonmusculoskeletal complaints in chiropractic practice: Report from a practice-based research program. J Manipulative Physiol Ther 2001;24:157-169.

27. Sawni-Sikand A, Schubiner H, Thomas RL. Use of complementary/alternative therapies among children in primary care pediatrics. Ambul Pediatr 2002;2:99-103.

28. Verhoef M, Papadopoulos C. Survey of Canadian chiropractors' involvement in the treatment of patients under the age of 18. J Can Chiropr Assoc 1999;43:50-55.

29. Astin JA. Why patients use alternative medicine. JAMA 1998;279:1548-1553.

30. Ebrall P. A description of 320 chiropractic consultations by Australian adolescents. Chiropract J Austral 1994;24:4-8.

31. Rubin D. Triage and case presentations in a chiropractic pediatric clinic. J Chiropract Med 2007;6:94-98.
32. Blum C, Globe G, Terre L, et al. Multinational survey of chiropractic patients: Reasons for seeking care. JCCA J Can Chiropract Assoc 2008;52:175-184.

33. Alcantara J. The presenting complaints of pediatric patients for chiropractic care: Results from a practice-based research network. Clin Chiropract 2008;11:193-198.

34. Bausell R, Berman B. Commentary: Alternative medicine: Is it a reflection of the continued emergence of the biopsychosocial paradigm? Am J Med Qual 2002;17:28-32.

Address correspondence to: Joel Alcantara, D.C.

International Chiropractic Pediatric Association 327 North Middletown Road Media, PA 19063

E-mail: dr_jalcantara@yahoo.com 